\title{
Status Quo Analysis and Optimized Scheme of In-plant Logistic Based on JIT
}

\author{
Jianhua Liu ${ }^{1}$, Ruijundi $\mathrm{Ma}^{1, *}$ and Mingzhao Wang ${ }^{1}$ \\ ${ }^{1}$ School of Management Engineering, Zhengzhou University, Zhengzhou 450001, China \\ 18037451189@163.com
}

Keywords: JIT, Kanbanmanagement, In-plant Logistic, Circulation Distributions

\begin{abstract}
Based on the basic concept of JIT and taking Zhengzhou Fengshen Logistics Co., Ltd. as an example, this paper focuses on the analysis of the logistics distribution process from acceptance, storage, and supply of KIT by means of investigation and statistical analysis. The paper finds that there are some problems in the whole process of logistics and distribution of the whole plant, such as low efficiency of employees, unreasonable distribution of the upper and lower levels, unreasonable distribution of the site, existence of cargo damage. At last, the paper puts forward the scheme of closed-loop material distribution through kanban management, and compares the inventory cost and distribution efficiency of the in-plant logistics before and after optimization. The optimized distribution efficiency is greatly improved and the inventory cost is greatly reduced. The paper will effectively improve the Zhengzhou Fengshen Logistics Co., Ltd. factory logistics and distribution operations, and give reference and inspiration to similar business
\end{abstract} third-party logistics enterprises.

\section{INTRODUCTION}

With the progress of scientific and the rapid increase in productivity, competition between enterprises is more and more intense. If enterprises want to maintain a high competitiveness and advantages, they need to focus on the research and development of core technology of their companies and improve core competitiveness. So in such a large background, many companies choose to focus on the development of their core business, and then they need other enterprises to complete their own non-core business resources. In such a development process, the logistics industry will gradually separated and then the third-party logistic enterprises show up. Logistics distribution is the main business of many third-party logistics enterprises. This kind of business can save time and resources for manufacturers and then,the conpany can focus on the development of core business and enhance their own competitiveness. The third-party logistics enterprises develop rapidly in recent years. However, there is still a certain gapfor how to achieve high efficiency better and on-time logistic distribution. JIT (Just in Time) is a production management mode developed by Japan's Toyota Motor Corporation to expand the scale and establish a mass production system, which is also called punctual production.The basic idea ofJIT can be summarized as "the product needed to produce the desired quantity when needed" (Longshi Han, 2013). Butactually on the use of the enterprise in the process, how to ensure timely delivery and product quality, how to achieve under the fine management of the minimization of inventory and maximize the efficiency of production is the constant pursuit of the enterprise.

Wenqian Jin's JIT inventory management cost analysis and implementation conditions based on WalMart. Through the JIT inventory cost of inventory management analysis shows that Wal-Mart's forward logistics and distribution system and flexible and efficient information network is how to effectively reduce the cost and out of stock cost and also achieve the best level of inventory investment. This paper also explains why it can not operate in China (Wenqian Jin, 2011). Ruize Sun's JIT design and design of JIT-based production and production of billboard distribution system is studied. JIT definition and thought, JIT electronic application and development, JIT principle and operation mode and JIT architecture are analyzed and analyzed Kanban management functions, types, rules, and implementation conditions (Ruize Sun, 2016). Yanchao LI's research on material distribution method of mixed-flow assembly line based on JIT procurement improved the application of material distribution method of punching and directing banner in mixed-flow assembly aine (Yanchao Li, 2013).Zhi Wei's SGMW factory logistics on-line distribution of the status quo analysis and optimization programs analyzes the comparison of line distribution and fuzzy distribution of the two distribution models. The paper comes to fuzzy distribution which will improve the overall efficiency (Zhi Wei, 2013). Jozsef Voros's process quality adjusted lot sizing and marketing interface in JIT environment analyzes the quality and efficiency issues existing in the JIT environment and analyzes the characteristics of the total cost of the demand function and proposes how to determine the optimal quantity of the contract (Jozsef Voros, 2016). Fardin Ahmadizar proposed a twoobjective ambiguous bidirectional supply chain planning method for supply chain planning under the dualobjective ambiguity environment and made a JIT assignment for the supply chain (Fardin Ahmadizar, 2013).

Based on the concept of JIT, the paper selects the factory of Dongfeng Nissan Passenger Car Company, the main business of Zhengzhou Fengshen Logistics Co., Ltd., and analyzes the status quo of the logistics process in the factory where the factory is located, and finds out the problems existing in the process of delivery. The paper establishs optimization model to improve the lack of logistics and distribution process in the factory, and puts forward suggestions for improvement. 


\section{THE ANALYSIS OF STATUS QUO IN IN- PLANT LOGISTIC}

Zhengzhou Fengshen Logistics Co., Ltd. mainly to do

Acceptance Warehouse

\subsection{The Analysis of Status Quo in Acceptance}

Acceptance is a process that the productfrom the supplier is confirmed whether satisfy the Dongfeng Nissan's contracting method, which is also known as the receipt business. However, the acceptance is not only the receipt, but also as the Dongfeng Nissan receipt window. As a supplier and the company's contact window, it represents the company's image. The normal operation of the vehicle and the efficiency of the unloading operation are the focus of the receiving business. When the abnormality is found, the monitor should be immediately reported and quickly corresponds to the exception.The acceptance process has the following problems:

(1) Quality: Zhengzhou Fengshen logistics co.,Ltd. is responsible for the acceptance of goods, but in normal circumstances, the inspectors are based on the receipt to determine the specific number of arrival consistently, which can not guarantee the quality of the arrival. For example, the arrival of the components were crushed or deformed, and there are abnormal parts into the situation, specifically in the arrival of the parts mixing with other products, or the number in large differences. The above situation is mainly that the acceptance of the work are generally confirmed by the inspectors, and people can't do things always right.As a large number of goods in the central warehouse every day, the work of the inspectors is very heavy. What's more, the quality of the guarantee should be sure by the suppliers. Choosing a good supplier will reduce the product's defective rate.

(2) The errors of number: when the inspector do the acceptance of the work, there will be some wrong in inventory of the number of goods. The inspector will also receive a single scan into the warehouse, so if the number of errors is found in the acceptance, it will lead to the production of the production line. The acceptance of the goods and the goods to check and confirm the label, and then receive a single scan into the library, the information system will have the end of the end of the goods handling machine abnormalities, as well as the existence of non-satisfied parts into the confirmation of the problem, the information problem is a line of employees can not be resolved, But these potential risks will lead to the production line.

\subsection{The Analysis of Status Quo in Warehouse Management}

The warehouse management has its purposeand scope of application.Producting management refers to "thenecessary things, in the necessary time, sent to the necessary places and to ensure the necessary quantity to maintain the quality of supply".The warehouse management is carried out through the implementation of the cycle check, etc., to achieve the actual inventory and theoretical inventory inspection and grasp the lack of inventory, excess situation, in order to prevent the bad is the car manufacturing plant logistics, and the logistics and distribution process within the factory are as follows:

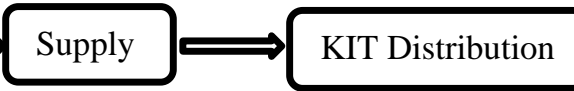

phenomenon like the lack of parts (the shortage of line parts). The warehouse management is applicable to the purchase of parts, semi-finished products and finished products (including stamping parts).

Firstly, the central warehouse of the existing problems are as follows: we should keep the parts have 8 hours of inventory in our daily life, which issafe inventory as well.There is a certain distance to the JIT zero inventory.Mainly the suppliers often don't arrive timely, so the reality must maintain a certain amount of safety stock. As the central warehouse is mainly placed in the domestic parts and the goods are more, so there will be too many goods and no place for them.Warehouse shelves are less and the space is not used enough. The goods are not standardized and the material level is not standardized, which lead to low transport efficiency.Forklift driver's work becomes difficult because it is not the best way to pick up.Transport path is not optimal due to the changes in Dongfeng Nissan operating plan, and the warehouse needs to make timely adjustments on the level. Of course, the current work is mainly by the workshop which is responsible for the operation of the class to complete.But usually the class is also responsible for the delivery of goods and other issues.It is difficult to have time to complete the optimization of warehouse space, so that the material level can not make timely adjustments, and the transport path is not Optimal which lead to low efficiency.

Secondly, KD warehouse is mainly responsible for the import of pieces, but the current production of most of the parts of the car have been made in China, only a small number of parts need to import.The current situation in the $\mathrm{KD}$ warehouseis different from the central warehouse, because the central warehouse has more goods leading to confusion while KD warehouse is not sufficient in the use of space, less goods but largespace. Warehouse uses the CATS system while the system may cause people to waiting for too long and affecting efficiency when the operator to query the job situation because optimization is not timely. In addition, there are inventory errors, and the required shelves are over needed while some do not meet the demand situation, which is due to regional planning is not very reasonable, and not timely in accordance with the number of goods to make adjustments.

\subsection{The Analysis of Status Quo in Supply Management}

The supply of logistics in the factory requires the necessary items and quantities to be supplied to the necessary places within the necessary time and to seek the lowest quality and cost. Zhengzhou Fengshen Logistics Co., Ltd. is mainly used in the supply of AGV car supply mode, synchronous supply mode, the order of supply, part of the synchronous supply, trolley direct 
supply, trolley partition supply, replacement supply, conversion packaging supply, Line side bare supply mode, forklift supply mode and so on.

\subsubsection{Waiting Parts and Stopping Line}

During the supply process, the staff of the tractor is not only responsible for the parts from the warehouse to the KIT assembly area but need to do the choice of parts out of the warehouse and feeding work at the same time. In addition, the transport path is not optimal which will affect the efficiency of the tractor driver and then affect the efficiency of the production line. Due to personal negligence or efficiency problems from the tractor driver, the production line required materials can not be transported to the line in time, and then cause the problem of material to be discontinued.

\subsubsection{Cargo Damage Situation}

Parts from the acceptance, storage to the supply chain are operated by the people.The handling of personnel, the use of forklifts and picking the parts are inseparable from the staff's operation. Due to unskilled staff and unreasonable transport routes, they will lead to cargo damage situation. Zhengzhou Fengshen Logistics Co., Ltd. month cargo damage reached as shown in Figure1:

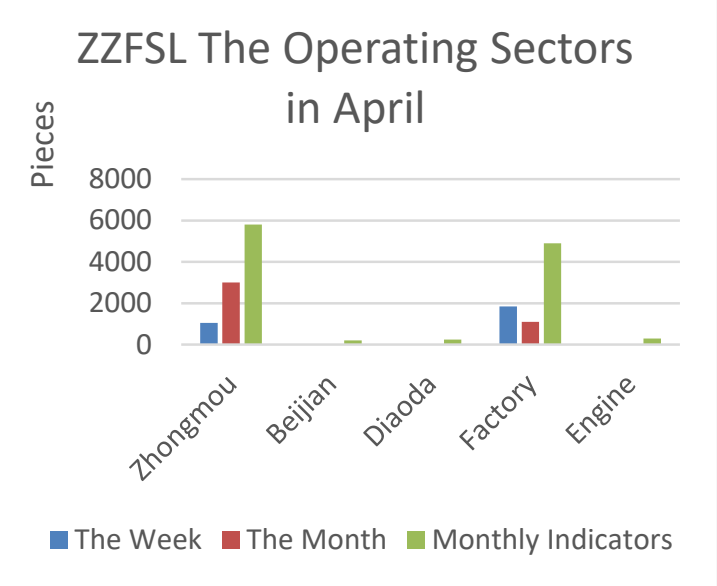

Fig.1 ZZFSL the operating sector in April a cumulative cargo damage situation

\subsection{The Analysis of Status Quo in KIT Distribution}

KIT distribution begins at the Japanese auto industry, which is based on JIT (justin time) production of automobile factory logistics model. In 2003, Dongfeng Motor Group's Fengshen Automobile and Japan Nissan Motor carried out a strategic reorganization and establishedthe Dongfeng Nissan, then the model of KIT distribution began to implement the relevant domestic factories. At present, Dongfeng Nissan Huadu factory, Xiangyang factory, Zhengzhou factory, Dalian factory, and Dongfeng commercial vehicles and other factories have been imported into the KIT distribution model. In the second half year of 2010, Zhengzhou Fengshen Logistics Co., Ltd. began to receive Dongfeng Nissan Zhengzhou factory KIT assembly project. Zhengzhou Fengshen logistics is the first company to master KIT technology in all Fengshen logisticscompanies, and also is currently the only one factory to get KIT distribution outsourcing in Dongfeng Nissan companies.
There are serval KIT distribution area problems from the following five aspects to analyze. Firstly, in the staff side, there is interference between personnel and work distance distance. Secondly, in mechanical side, AGV can not automatically release, and the parts of AGV have some defectives. The process of unreasonable need to manually push; Thirdly, in material side, the difference between the pieces with a high rate of error through the AGV return bad product. Fourthly,in operating methods, the staff compiled into imperfect, uneven distribution of the distribution of spare parts in the process of damage to the division of responsibility with the car returning more rubbish. Lastly, in design and planning side, the material level is far from anti-fade system switch, and trolley is far from the material. What's more, fabric design of Packing is unreasonable and collecting parts to take parts is inconvenient. KIT error with the control as shown in Figure 2:

\section{ZZFSL KIT error rate in 2014}

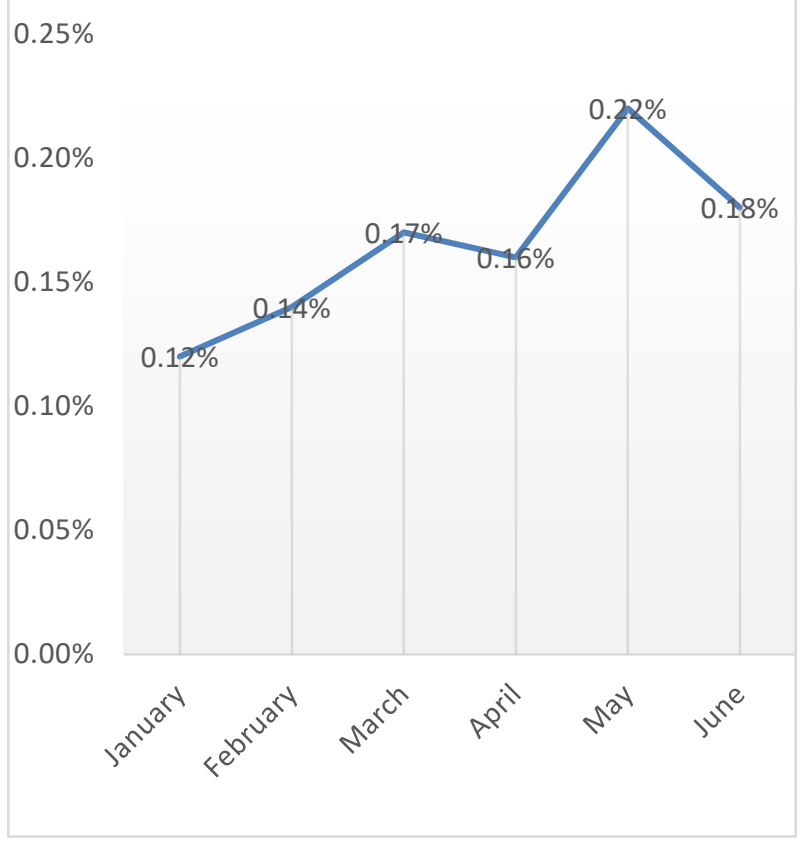

Fig.2 ZZFSL in the first half of the KIT error rate

\section{CIRCULATION DISTRIBUTION IN IN-PLANT LOGISTIC}

\subsection{The Concept of Kanban Management}

The method of kanban management is a transfer in the same process or before and after the process of logistics or information flow. JIT is a pull-management approach, which requires information from the last process through the flow of information to the last process of transmission of information, and the carrier of this information is called Kanban. JIT is impossible without a Kanban. Therefore, JIT production methods are sometimes called kanban production methods. Once the master productionplan is finalized, production orders will be issued to each production workshop. And then, each production workshop will issue production orders to 
each process in front of it. Finally, corresponding instructions will be issued to the warehouse management department and purchasing department. The delivery of these production instructions is done via Kanban (Zhanqi $\mathrm{Du}, 2005)$.

\subsection{JIT-based material distribution process}

In this way to the production line on the various parts of the material distribution process is as follows. Warehouse is a company's material distribution center.
After the parts of the distribution, the need for a reasonable cycle in accordance with the design of the line on the production line in order to ensure the smoothprogress of production. At the same time, the warehouse also need to receive the production line of the request and prepare the next cycle of distribution. The entire process begins and ends all in the warehouse, which is a closed-loop pull production process. The specific process can be seen in the Figure 3

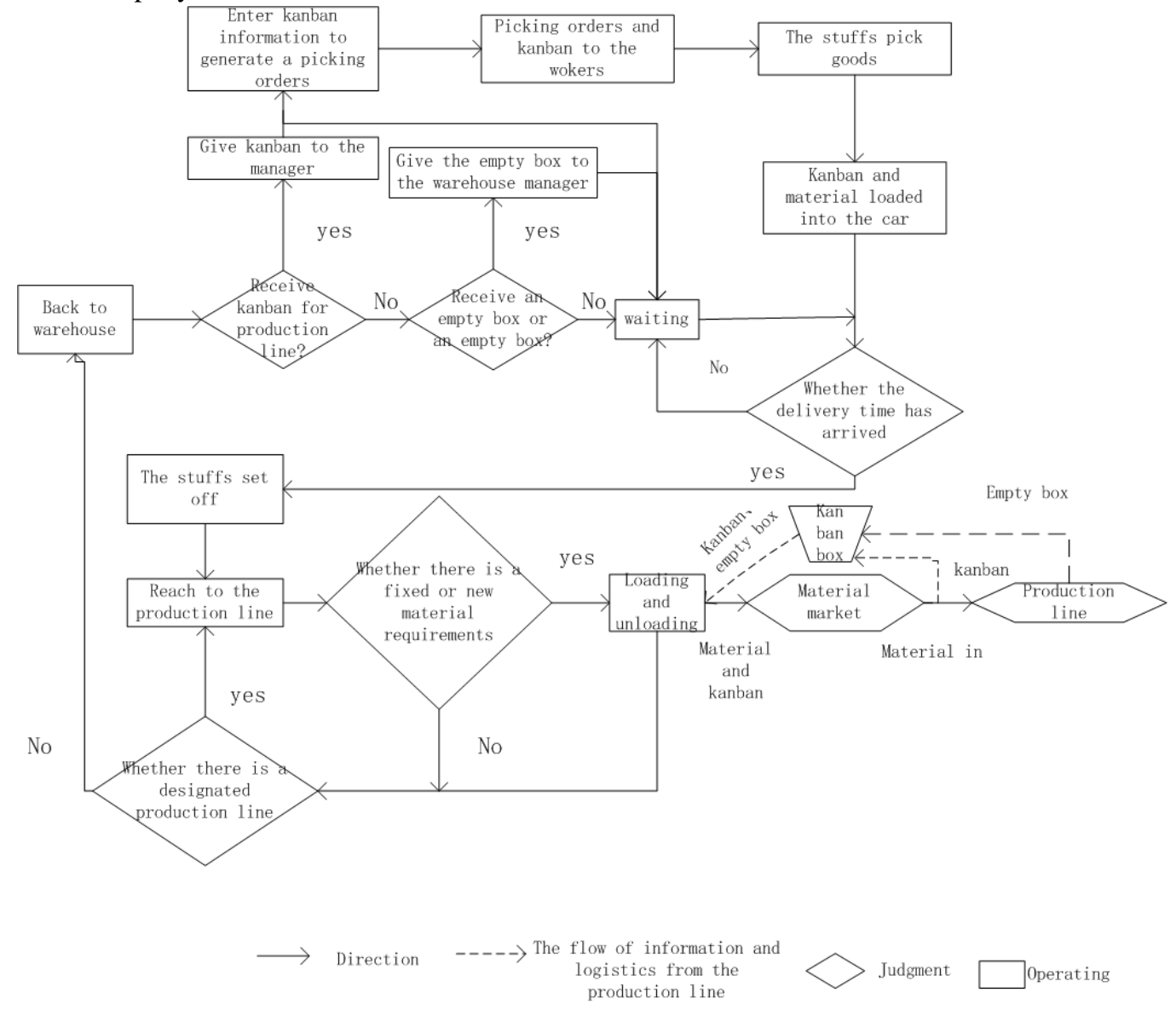

Fig.3 JIT-based logistics cycle delivery process

In the entire kanban system, the production line can quickly pass replenishment information to ensure that the warehouse on the material information transmission, timely response and line edge inventory control. As shown in the Figure, the warehouse is the starting point and the end point of the entire distribution system, and the distribution staff will be delivered to the warehouse after the card.You need to wait until the next delivery time, and then complete the production line of centralized distribution.The staff of the production line need to attach the material on the kanban into the kanban box at the same time.As the demand for information release, they also need to return the empty empty containers. Through the close cooperation between the two systems, you can achieve small batch, multi-batch delivery of punctuality (Junrong Pan, 2016).

\subsection{The Requirements of Logistics Circulation Distribution Process}

\subsubsection{Draw up a Standard Operating Book}

In the enterprise logistics and distribution links, the staff of the operating norms will directly affect the efficiency of the work.The standard operating book can clear all kinds of continuous operations (walking, handling, take parts to take place), and easy to find a waste of operations, accumulation, recklessness and so on. When the leader of the length of the operation observe the time, you can observe the work of one component, and also in accordance with a series of processes to guide the operation (Xu Liu, 2015).

\subsubsection{Establish a Sound Information Feedback Mechanism}

According to what we know, Zhengzhou Fengshen Logistics Co., Ltd. is generally by oral or opinion box to feedback staff work in the problem, which is not an efficient and standardized feedback mechanism. The views of employees should be conveied to the top leader timely. There should not have communication barrier between the upper and lower employees in order to enable the company to provide customer more satisfied services. Working in front of the staff is the driving force 
behind the development of the entire enterprise.

\subsubsection{Expand the Technical Team business}

A subordinate department of Zhengzhou Fengshen Logistics Co., Ltd. Zhengzhou factory logistics department is a comprehensive technical department. For a third party logistics enterprises, high quality and efficient service is very popular with customers. The technology department is a very critical sector because its optimization of the overall layout directly affects the productivity of the customer's company. The best placement of the parts into the entire plant layout is something that the technology department needs to consider. But in reality, the warehouse material design and adjustment of the location of the squad leader is responsible for the operation. I think this should be the responsibility of a dedicated technical department, so as to from the macro point of view to control the entire plant logistics distribution process.

\section{THE COMPARISON OF DISTRIBUTION OPTIMIZATION EFFICIENCY BEFORE AND AFTER}

Taking the assembly shop of Logistics Department of Zhengzhou Fengshen Logistics Co., Ltd. as the research object, the optimization was compared before and after optimization from several aspects such as inventory cost, inventory turnover, replenishment efficiency and delivery efficiency.

\subsection{Calculation Formula}

The inventory turnover rate is the ratio of the cost of the main business and the average inventory balance of the enterprise during a certain period, which is used to reflect the turnover speed of the inventory. Inventory turnover (times) $=$ cost of sales $\div$ average inventory.

Distribution efficiency $=$ the actual average delivery of employees within a unit of working time $\div$ the theoretical delivery of staff within a unit of working time $\times 100 \%$ (Zhi Wei, 2013)

\subsection{The Results of Comparison}

According to the data derived from the system derived by Zhengzhou Aeolus Logistics Co., Ltd. in April 2016, the following conclusions can be drawn: Firstly, the demand for the material in the warehouse by the line side will become more balanced, the consumption of the material in the line side will keep pace with each warehouse. The inventory of the warehouse is reduced, which reduces the cost of the inventory.

Secondly, the material flow speed on the production line becomes faster. The inventory turnover rates of domestically-made warehouses, KD warehouse and workshops are greatly increased.

Thirdly, the warehouse has a higher degree of specialization in terms of material distribution, and greatly improves the delivery efficiency, and increases the replenishment efficiency and reduces the waste of manpower and time.

Finally, make the logistics distribution process of the whole factory more efficient, simple and clear.

\section{CONCLUSIONS}

Zhengzhou Fengshen Logistics Co., Ltd. as a thirdparty logistics companies to provide customers with firstclass logistics services. Of course, the companies also need to continuously improve their productions, reduce costs, in order to have a better competitive advantage. From the papert in in-plant logistics cycle distribution process shows that if they pursue a punctual system of in-plant logistics, which means the pursuit of "zero inventory" status, they need to use the method of circulation distribution than the traditional method of material distribution more effective and more in line with JIT concept. In the real distribution process, there will still be a certain amount of inventory either line or warehouse. The use of such replenishment methods will increase the efficiency of delivery, reduce inventory costs. It is a good choice for Zhengzhou Aeolus Logistics Co., Ltd.

\section{REFERENCES}

[1] Fardin Ahmadizar, 2013. Minimizing makespan in a group shop with fuzzy release dates and processing times, The International Journal of Advanced Manufacturing Technology. (66), pp.9-12

[2] Gábor Rappai, 2016. Process quality adjusted lot sizing and marketing interface in JIT environment, Applied Mathematical Modelling. (2), pp.20-21.

[3] Junrong, Pan, 2016. A comparative study of Kanban pull and production pull system [J]. Logistics Engineering and Management, Logistics Engineering and Management. (09), pp.90-91.

[4] Longshi, Long, 2013. Analysis and optimization of automobile JIT production, Logistics Technology and application. 18(09), pp.101-104.

[5] Rui, Ze, 2016. Research and design on the JIT-based Kanban distribution management system for automobile vehicle manufacture and production, Southwest Jiao Tong University. (09), pp.101-104.

[6] Wen, Qian, 2011. Cost analysis and implementation conditions of JIT inventory management -- Taking Wal-Mart Store Inc as an example, the ideological front. 37(1), pp.98-99. [7] Xu, Liu, 2015. Research and implementation of automobile aftermarket parts logistics management system for cycle distribution, Southwest Jiao Tong University. (09), pp.102-105. [8] Yanchao, Li. Research on material distribution mode improvement of mixed model assembly line based on JIT purchasing, Tsinghua University. (09), pp.101-104.

[9] Zhanqi, Du, 2005. Application analysis of Kanban management in JIT production, Tech Information Development \& Economy. (20), pp. 215-217.

[10] Zhi, Wei, 2013. Status analysis and optimization scheme of on line logistics distribution in SGMW plant, China Storage \& Transport. (08), pp.105-107. 